\title{
CO-WORKERS SUPPORT AND JOB PERFORMANCE
}

\author{
Irina loana PELIN \\ Babes-Bolyai University, Romania

\section{Codruta OSOIAN} \\ Babes-Bolyai University, Romania
}

\begin{abstract}
In the context of a global pandemic affecting businesses worldwide, management focus is oriented to what would enhance the employees' work performance even in crisis situations. This paper aims to identify, explore and explain the relationships between social support, task performance and organizational citizenship behaviour as well as different demographic data which might influence these variables. The final goal is to propose relevant solutions and recommendations for managers and practitioners in human resources which could be easily applied and have a major impact on individual performance as well as on the overall performance of the organization. The quantitative research is based on a sociological survey consisting of two standardized questionnaires based on tested Likert scales measuring co-workers perceived support, employees' task performance and organizational citizenship behaviour. The sample consists of 300 pairs of employees and their direct supervisors working in services companies based in Romania. The survey's results are analysed by performing correlation and regression analyses in JASP 0.14.1.0 free software. The results show positive relationships between the variables yet it proves that co-workers' support is not relevant for task performance. Valuable information regarding OCB and task performance can be added to the previous job performance research. Statistically significant relationships with demographic data could not be obtained. Further studies might consider a larger sample consisting of Europeans in more than one country as well as comparative analyses between countries and companies' fields of activity.
\end{abstract}

Key words: workplace social support, task performance, organizational citizenship behaviour, extra-role performance, co-workers support

JEL classification: M12

\footnotetext{
* Corresponding author. Address: Department of Management, Faculty of Economics and Business Administration, Babeș-Bolyai University, Cluj-Napoca, Romania, 400591 Th. Mihali Street 58-60, Tel. +40 264 418655, Fax. +40 264 412570, irina.pelin@econ.ubbcluj.ro
} 


\section{Introduction}

Since 2020, the global pandemic has been one of the most challenging factors affecting businesses worldwide. Although we are living in the era of technology where information flow is faster than anything, being forced to move to a digital world has been tough for everyone, in some countries more than in others. A lot of changes appeared in various fields of activity and it confused plenty of human beings in regard with their new normal. Managers and human resources (HR) managers had to find the best way to ease the work and improve job performance of their employees or at least, keep it at the optimal levels existent before the pandemic.

Taking into consideration the fact that everyone's "new normal" included lack of social interaction, the necessity of research on the social support and job performance topic emerged. The small detail that might make the difference can be daily social interaction everyone had in the workplace consisting of informal interactions, organizational citizenship behaviours (OCB) and other activities. The scarce literature in the field raised some further proposals from which the current research started. This paper's purpose is to bring new information relevant for the European workforce market as previous studies on the topic were only a few and were focused more on the Asian or American countries' population. Precisely, it aims to formulate pertinent recommendations and solutions for HR practitioners and managers in Europe, with a focus on Eastern Europe, which will help in facing unfortunate events like global crises whilst keeping organizational outcomes at a desired level.

This paper is based on quantitative research to explain and identify the relationship between social support and job performance. The data was collected via two standardized questionnaires consisting of Likert scales measuring coworkers' support in employees' case and task performance and OCBI (individual organizational citizenship behaviour) in supervisors' case. The research design is also a novelty element brought by the current survey seeing that little research on the topic used supervisor's evaluation instead of self-evaluation.

In the following sections of this paper, relevant and valuable literature in the field will be briefly presented as well as the methodology used and the results, discussions, limitations, and practical implications.

\section{Literature review}

To have an in-depth overview on the theoretical concepts, this paper works with, relevant aspects in the literature will be presented trying to explain the workplace social support, job performance and organizational citizenship behaviour as well as different relationships identified between these variables.

\subsection{Social support in the workplace}

Social support in the workplace is explained as a set of actions or behaviours aimed to help others at the workplace (Deelstra et al., 2003 apud Harris et al., 2007) performed by both colleagues and supervisors (Karasek and Theorell, 1990 apud Chou, 2015). This kind of behaviours consist of mentoring, emotional support, 
offering task and problem solving support or just informing others about hierarchies in the organization (Hill et al., 1989 apud Harris et al., 2007). Hobfoll (1988 apud Chou, 2015) emphasized the importance of co-workers as key resources of the employees. Mentoring as workplace social support type (Hill et al., 1989 apud Harris et al., 2007) is defined as an organizational activity in which an employee with higher work experience in the organization is supporting a new hired or someone promoted in a new position by guiding them with both technical and organizational knowledge (Pânișoară and Pânișoară, 2016). Jenssen et al. (2018) conducted a qualitative study in which were involved employees from different companies in Netherlands and showed that mentoring relationships can improve individual performance for both mentor and protégé leading to the future overall development of the organization. Taking this into consideration, the current paper will focus on co-workers' support as workplace social support.

\subsection{Job performance}

Job performance, as key concept of the current paper, is a multi-dimensional concept according to various authors describing it (Sonnentag, Volmer and Spychala, 2008). On short, job performance is the extent to which an employee achieves specific standards established by the organization (Nayyar, 1994 apud Muchhal, 2014) and can be also described through those individuals' behaviours which are relevant for the organizational objectives (Muchhal, 2014).

Job performance is perceived as the result of one's behaviour on the one hand and as behaviour, on the other hand (Sonnentag et al., 2008). Armstrong (2018) states that in performance management, there should be taken into consideration both the results and the behaviours that lead to those results. This mention is consistent with the literature stating that there exist different types of job performance, two of which being the most popular: task performance and contextual performance (Muchhal, 2014). Task performance refers to those activities specific to a certain position and differs from a position to another whilst contextual performance consists of activities which are common to a variety of job types (Muchhal, 2014). Summarily, task performance includes achieving all the activities mentioned in the job description whilst contextual performance covers organizational citizenship behaviour and pro-active attitudes (Muchhal, 2014). Last but not least, adaptive performance is the third type of performance identified however not as researched as the first two (Campbell et al., 1993 apud Sonnentag et al., 2008). It mostly regards one's ability to adapt explained through plenty of dimensions such as crisis management, stress management, problem solving, etc. (Pulakos et al., 2000 apud Sonnentag et al., 2008).

\subsection{Organizational citizenship behaviour}

Organizational citizenship behaviour is the last key concept of this current paper and therefore, it will be briefly explained. As previously stated, it is the stable part of the contextual dimension of performance (Muchhal, 2014). It is known as a freewill or pro social behaviour, separated from the mandatory tasks required in the job description of an employee (Jha and Jha, 2010). Throughout the time, studies demonstrated that organizational citizenship behaviour leads to organizational 
success, enhancing productivity, effective use of resources and overall performance (Tambe and Shanker, 2014). Organ (1997 apud Tambe and Shanker, 2014) defines the organizational citizenship behaviour as those contributions an individual brings to the development of social and psychological context, supporting task performance. Williams and Andersen (1991 apud Jha and Jha, 2010; Tambe and Shanker, 2014) divided this concept into two categories: OCB-I (interpersonal organizational citizenship behaviour) which is oriented towards individuals and OCB-O which is oriented towards the organizational level. Some of the factors determining OCB are the following: Individual dispositions such as positive or negative affectivity and agreeableness might predict OCB according to Organ and Ryan (1995, apud Jha \& Jha, 2010); Group cohesiveness - employees' work group tends to have a high influence on individuals' attitudes and behaviours (Jha \& Jha, 2010) and when the group is cohesive, individuals are more sensitive about supporting others (Schachter et al., 1951 apud Jha and Jha, 2010). Organ (1990 apud Jha \& Jha, 2010) explained the fact that the work group may predict OCB through social exchange theory, OCBs appearing as an effort group members make in order to maintain the exchange relationships in the group; Employee attitudes - the positive attitudes such as job satisfaction or organizational commitment seem to be the ones determining OCB; Leader-member exchange; Organizational justice.

\subsection{Social support and job performance}

Although all the three concepts explained above are widely studied, research on the relationships between these variables seems to be exiguous. Amarneh et al. (2010) conducted a correlational and descriptive study on the effect of co-workers support on job performance among medical staff in Jordan. A positive relationship was discovered between co-workers support and job performance. Contradictorily, Tran et al. (2018) showed that between Vietnam nurses only supervisor's support is a direct predictor of job performance whilst co-workers' support is not relevant. According to Park et al. (2004), a high perceived workplace social support is positively linked to a higher level of work control, lower depression level and higher work performance. Following Talebzadeh and Karatepe's study in 2020 on flight attendants from three different companies, it seems that work engagement mediated co-workers' and supervisor's effects on job satisfaction, task performance, creative and extra-role performance. Social support from co-workers is not significant for task performance yet is a key resource for extra-role and creative performance (Talebzadeh and Karatepe, 2020). Aydin and Tuzun (2019) found that both co-workers' and supervisor's support are linked to both in-role and extra-role performance. A theoretical approach provided by Chiaburu and Harrison's meta-analytic study in 2008 brings valuable information for the current study. It was proven that coworkers represent a great resource for employees' efficiency, significant positive relationships being discovered between their support and both task performance and organizational citizenship behaviour (Chiaburu and Harrison, 2008). Consistent explanations for the positive relationship between workplace support and organizational citizenship behaviour can be found in the reciprocity theory (Gouldner apud Chiaburu and Harrison, 2008). Despite the existent evidence, there is a strong need for more consistent findings on the relationship between social support and job performance, 
with a focus on the relationship between task performance and social support as well as social support and different dimensions of OCB.

\section{Methodology}

The current research is based on quantitative data and aims to identify the existence of different relationships between co-workers' support, task performance and $\mathrm{OCBI}$ as well as their power and direction. Therefore, the current paper tries to be an explanatory survey rather than a descriptive one (Chelcea, 2001).

The present research formulates three main hypotheses based on the above stated literature review:

H1: Higher perceived co-workers' support is positively linked with higher task performance.

H2: Higher perceived co-workers' support is positively associated with a stronger tendency to manifest organizational citizenship behaviours. behaviours.

H3: A high task performance is positively linked with organizational citizenship

To collect the data, two standardized questionnaires were used as research instruments and were filled in by pairs consisting of employees and their direct supervisors. The questionnaires were self-administered and were sent via online platforms to the respondents. The research design provides good accuracy in job performance assessment, since it is not based on self-evaluation, but on the feedback provided by their direct supervisors are in charge of it.

The sample consists of 300 pairs of respondents, employees and their direct supervisors working in services, hospitality, and IT organizations from Romania. The average age of the respondent employees is 30 and their organizational tenure is 2.93 years, whilst supervisors' average age is 39 and organizational tenure is 8 years.

The questionnaires use Likert scales. The scale measuring perceived coworkers support (Susskind et al. 2001) aims to identify the link between employees' perceptions and attitudes towards work in services companies and customers' satisfaction. Their hypothesis was that co-workers support is positively linked to customer orientation and customer satisfaction. The items are scored from 1 to 7 , where 1 stays for "totally disagree" and 7 stands for "totally agree". Task performance scale was used by Liden, Wayne \& Stilwell (1993) in their longitudinal survey on leader-member exchange. It consists of 4 items scored on a scale from 1 to 7 , where 1 stands for "totally disagree" and 7 stands for "totally agree". The OCB-I scale contains 5 items scored from 1 to 7 where 1 stands for "never" and 7 stands for "always". These items were extracted from Lee \& Allen's survey in 2002 on OCB and WDB (work deviant behaviour) which were chosen from a pool of different scales' items measuring OCBs, scales that were tested and validated before.

All the three scales went through a single-test analysis conducted in JASP 0.14.1.0 in order to test their internal consistency. Tables 1, 2 and 3 show good internal consistency of the scales. 
Table 1. Co-workers support scale reliability

Frequentist Scale Reliability Statistics

\begin{tabular}{rr}
\hline Estimate & Cronbach's $\boldsymbol{\alpha}$ \\
\hline Point estimate & 0.897 \\
\hline
\end{tabular}

Table 2. Task performance scale reliability

Frequentist Scale Reliability Statistics

\begin{tabular}{lr}
\hline \multicolumn{1}{c}{ Estimate } & Cronbach's $\boldsymbol{\alpha}$ \\
\hline Point estimate & 0.907 \\
\hline
\end{tabular}

Table 3. OCBI scale reliability

Frequentist Scale Reliability Statistics

\begin{tabular}{cr}
\hline Estimate & Cronbach's $\alpha$ \\
\hline Point estimate & 0.882 \\
\hline
\end{tabular}

As control variables, both employees and supervisors indicated their age, sex, education level and organizational tenure in years. In the current paper, some analyses were conducted using demographic data as well.

\section{Results}

To analyse the results, correlation and regression analyses were conducted using JASP 0.14.1.0 free software.

\subsection{Co-workers support and task performance}

Testing the first hypothesis, the Pearson correlation showed no statistically significant relationship between the variables. The findings reveal a positive relationship, showing that the presence of perceived co-workers' support is associated with increased task performance (Table 4). The hypothesis was confirmed only partially. This result is consistent with other studies which showed that co-workers' support is not relevant for employees' task performance (Tran et al., 2018; Talebzadeh and Karatepe, 2020). On the other hand, the findings contradict other studies, which revealed that coworkers' support is significant for task performance (Chiaburu \& Harrison, 2008; Amarneh et al., 2010; Park et al., 2004).

Table 4. Co-workers' support and task performance

Pearson's Correlations

\begin{tabular}{llrr}
\hline \multicolumn{1}{c}{ Variable } & & Co-workers support & Task performance \\
\hline 1. Co-workers support & Pearson's $r$ & - & \\
& p-value & - & - \\
2. Task performance & Pearson's $r$ & 0.107 & - \\
\hline
\end{tabular}

${ }^{*} p<.05,{ }^{* *} p<.01,{ }^{* * *} p<.001$ 
Graphic 1. Regression graph - co-workers' support and task performance

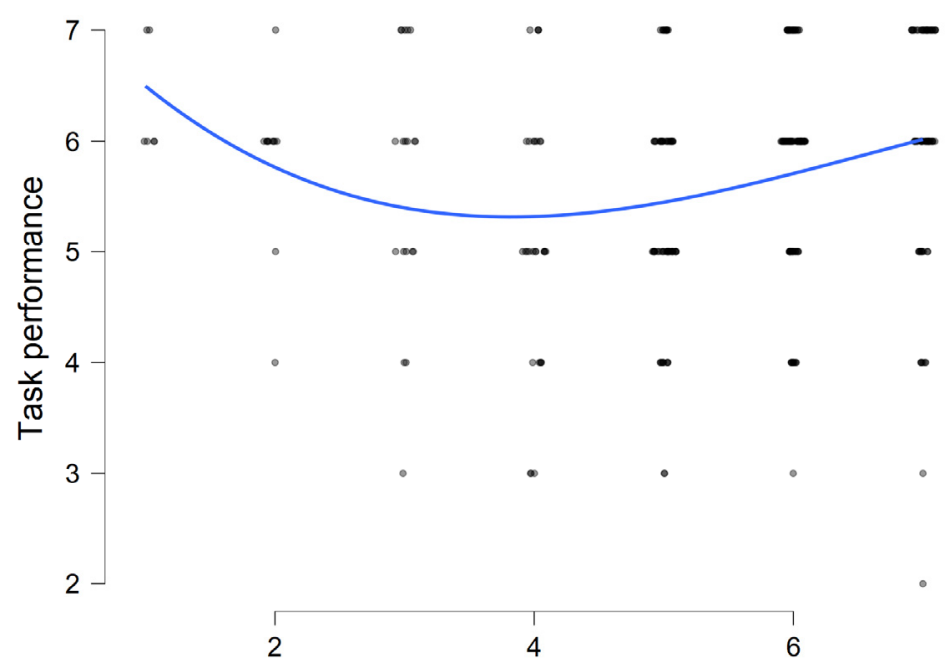

Co-workers support

According to the regression graph, a high task performance is mostly predicted by either a low or high level of perceived co-workers' support, moderate levels of co-workers' support being associated with a medium task performance. Potential explanations were not found in the verified literature yet might exist in studies regarding social support or job performance.

\subsection{Co-workers support and organizational citizenship behaviour}

Table 5. Co-workers' support and OCBI

Pearson's Correlations

\begin{tabular}{llcc}
\multicolumn{1}{c}{ Variable } & & Co-workers support & OCBI \\
\hline 1. Co-workers support & Pearson's & - & \\
2. OCBI & p-value & - & - \\
& Pearson's & $0.285^{* * *}$ & - \\
\hline
\end{tabular}

${ }^{*} p<.05,{ }^{* *} p<.01,{ }^{* * *} p<.001$

As Table 5 illustrates, there is a strong and positive correlation between coworkers' support and organizational citizenship behaviour. This result is consistent to other findings in the literature (Talebzadeh \& Karatepe, 2020; Aydin \& Tuzun, 2019) showing that high co-workers' support is associated with high organizational citizenship behaviour and vice-versa. The relationship may be explained through reciprocity theory (Gouldner, 1960 apud Chiaburu \& Harrison, 2008) or social exchange theory (Blau, 1964 apud Chiaburu \& Harrison, 2008). Social exchange theory is mostly explained through social interactions which lead to social obligations (Emerson, 1976 apud Cropanzano \& Mitchell, 2005) and it is based on the reciprocity norms studied by Gouldner (1960). On short, these norms state that when someone offers 
something, something will be returned as well and usually, the reciprocity norms are influenced by the individuals' culture (Cropanzano \& Mitchell, 2005).

Therefore, the second hypothesis of the study was also confirmed and the regression graph (Figure 2) supports Pearson correlation illustrating the fact that high perceived co-workers' support is associated with employees' OCBls, returning the help received in a way or another.

Figure 2. Regression Graph - Co-workers' support and OCBI

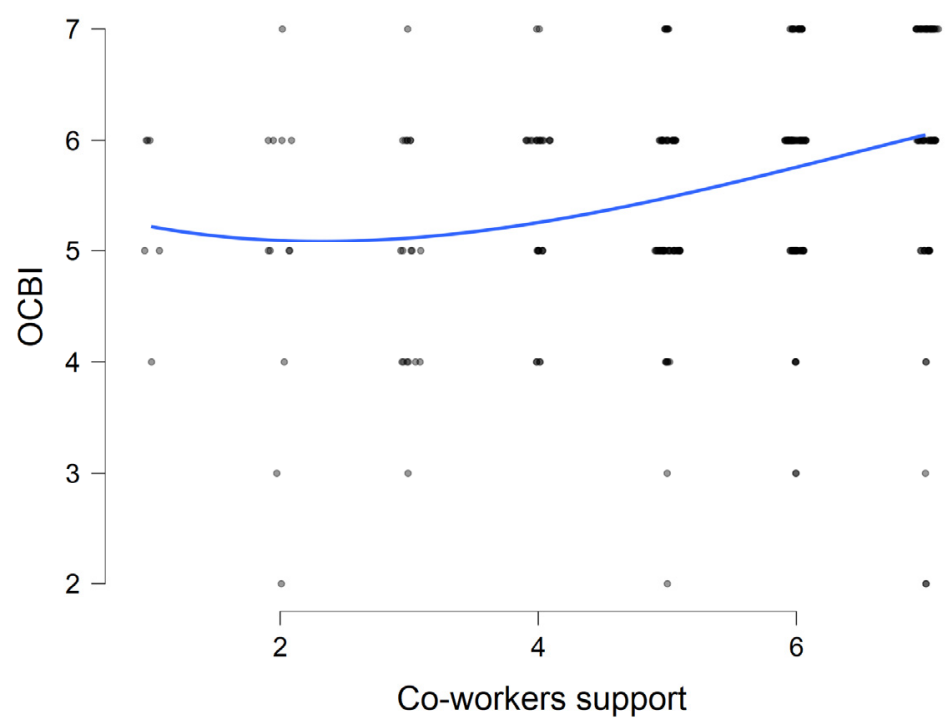

\subsection{Organizational citizenship behaviour and task performance}

Within the complexity of job performance, two popular dimensions are the task performance and extra-task performance, including here organizational citizenship behaviours. In table 6 , there can be seen a statistically significant and positive correlation between organizational citizenship behaviour and task performance. Both variables, as dimensions of the performance, seem to be related to each other positively and thus, the third hypothesis is confirmed.

This means that high performers tend to engage in OCBIs yet those who manifest this type of behaviours, might also exceed in their job tasks.

Table 6. Organizational citizenship behaviour and task performance

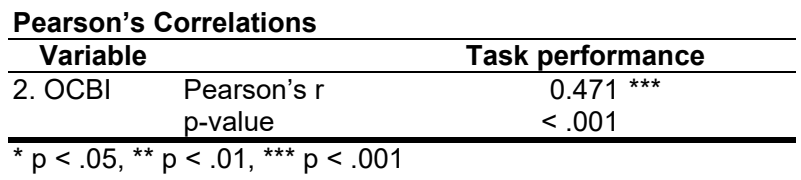


Previous studies, although insufficient, provide some explanations supporting the current findings. Hoffman et al. (2007) conducted a meta-analysis aiming to distinguish between OCB and task performance and to examine the relationship between the two variables as well. Their results show that task performance and OCB are distinct concepts, yet highly and positively linked to each other. Nasir et al. (2011) conducted a correlational survey on OCB and task performance, having supervisor's ratings for task performance and revealing a positive and significant link between these variables as well. Another survey conducted by Bruque et al. (2015) found a positive and linear relationship between OCB and task performance whilst other findings indicate a curvilinear relationship between the two variables (Rapp, Bachrach \& Rapp, 2013 apud Bruque, 2015). These findings are also consistent with what is revealed within the current survey, curvilinear relationships being showed in Graphic 3 and 4 showing how one variable is modifying in relationship to the other.

\section{Graphic 3. Regression Graph - OCBI and task performance}

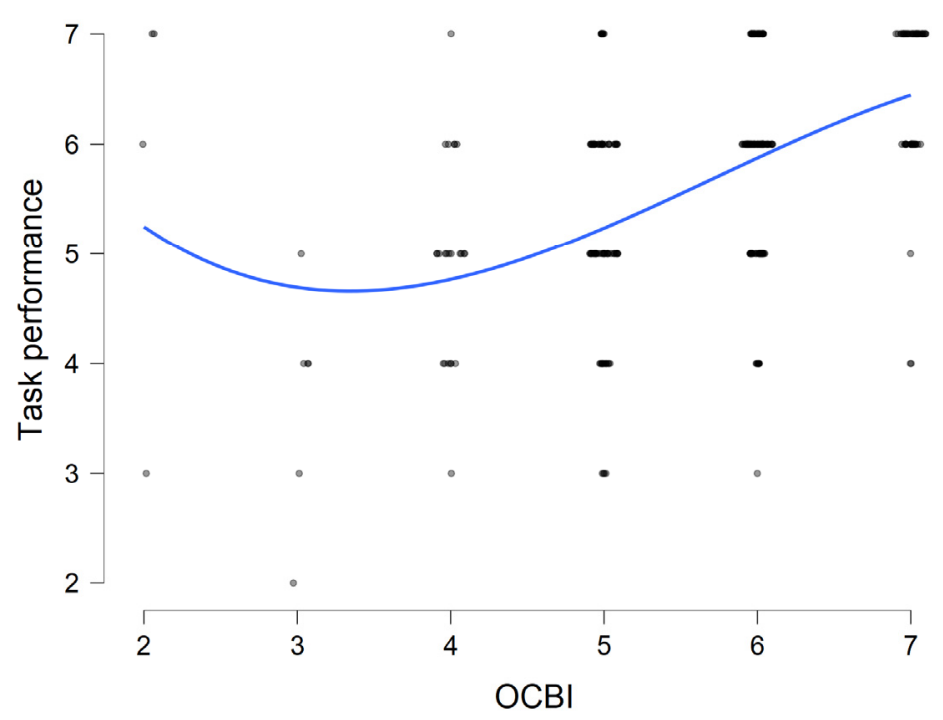

According to Graphic 3, it can be seen that only an increased level of manifesting OCBI leads to higher task performance. This can be explained through Janssen et al. (2011) survey's results showing that mentoring programs improve the performance of both mentors and protégés. 


\section{Graphic 4. Regression graph - Task performance and OCBI}

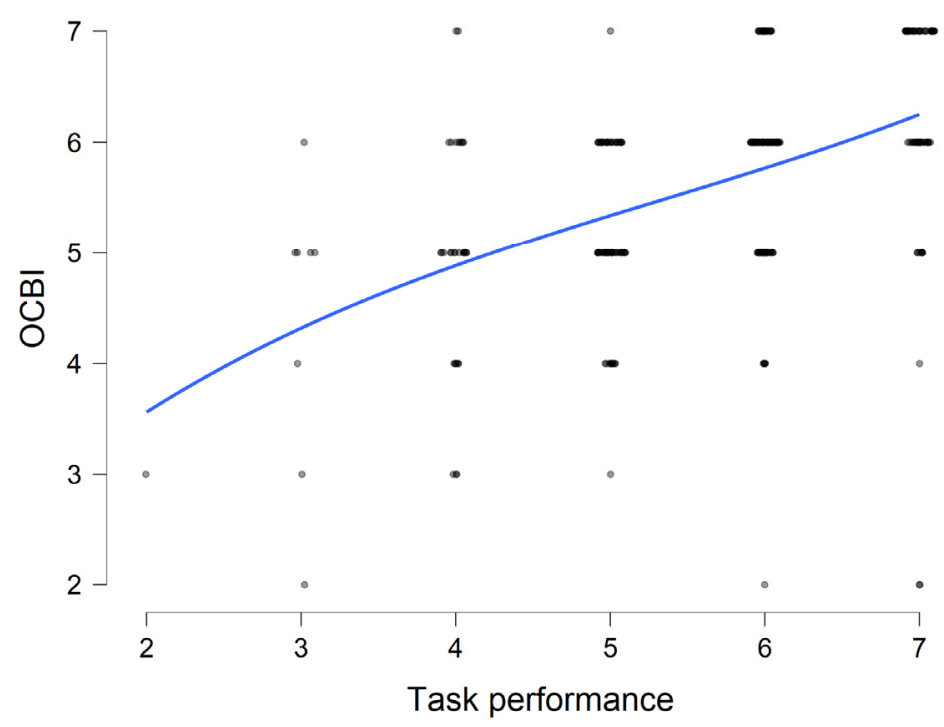

Graphic 4 illustrates that high level of task performance lead to high involvement in interpersonal organizational citizenship behaviours. This means that high performers tend to manifest OCBls due to the fact that they are key resources for others through sharing valuable information regarding in-role activities and general information about the organization (Hobfoll, 1988 apud Chou, 2015).

Demographic data proved to be irrelevant in predicting task performance, OCBI or perceived co-workers' support. Analyses conducted resulted in poor statistically significant relationships between the variables.

\section{Discussion and conclusions}

The current survey's results revealed positive and statistically significant relationships between co-workers' support and OCBI as well as between OCBI and task performance. Two out of three hypotheses were confirmed. However, unlike expected, there was no significant relationship between co-workers' support and task performance. However, future studies may try to use co-workers' support as a mediator. It is highly linked to $\mathrm{OCBI}$ and $\mathrm{OCBI}$ is highly and positively linked to task performance.

On one hand, the results illustrate how reciprocity norms and social exchange theory apply in organizations by enhancing the work environment and supporting the overall productivity and performance as well. This is a future direction which should be perpetuated in order to have a deeper insight in how it works and what can be done on purpose to build and maintain teams defined by helpfulness and positivity whilst taking measures to avoid work deviant behaviours and general negativity.

On the other hand, these results emphasize the difference between task performance and OCB and focus on their significant relationship. High performers 
tend to engage in behaviours oriented towards others while these behaviours enhance individuals' task performance. This study brings new information to the literature studying both OCB and task performance whilst very few studies focus on the link between them.

A limitation of the survey is related to the convenient sample, which makes the results impossible to generalize to the general population. Thus, further studies should explore the relationship between social support and task performance applied on randomised samples and in various contexts. For future studies in this field, using qualitative research methods might be a great advantage to obtain indepth results on the topic and suggest potential explanations for the non-convergent findings. It is also recommended to perform a more complex research design by introducing mediators or moderators of the relationships and perpetuate the social exchange theory. For more practical implications, studies can be conducted comparing different fields of activity in terms of co-workers' support relationship with task performance and OCBI.

\section{Practical implications}

As one of the main purposes of this current paper was to formulate practical recommendations for managers and human resources managers, few ideas will be briefly presented based on the results.

Although co-workers' support does not have a direct relationship with task performance, it is highly connected to OCBI which is in turn, related to task performance. Therefore, one of the recommendations would be to encourage social interaction and helpful behaviours between co-workers through programs such as work buddy and having coffee together in the mornings, things which can be applied in both online and offline contexts.

Giving the fact that manifesting $\mathrm{OCBI}$ is linked to high task performance, $\mathrm{HR}$ managers might think of different types of rewards to encourage OCBs generally as well as OCBIs. The rewards might be material or a simple public recognition of such behaviours.

Lastly, another proposal is to implement formal mentoring programs which can be developed both online and offline, for the new hires. Besides an informal buddy, a mentor in an experienced colleague will help in increasing task performance as well as exchange of helpful behaviours.

These proposals should be seen more as starting points which can be developed by the HR managers who can elaborate more specific solutions based on internal studies.

\section{References}

Amarneh, B. H., Abu Al-Rub, R. F., and Abu Al-Rub, N. F. (2010). Co-workers' support and job performance among nurses in Jordanian hospitals. Journal of research in nursing, 15(5), pp. 391-401.

Armstrong, M. (2006). Performance management: Key strategies and practical guidelines. 3rd ed. London and Philadelphia: Kogan Page Limited. 
Aydın, E., și Kalemci Tüzün, I. (2019). Organizational support sources and job performance relations: what about occupational commitment? Anatolia, 30(3), pp. 379-389.

Bruque, S., Moyano, J., \& Piccolo, R. (2016). OCB and external-internal social networks: effects on individual performance and adaptation to change. The International Journal of Human Resource Management, 27(1), 1-22.

Chelcea, S. (2001). Metodologia cercetării sociologice: metode cantitative și calitative. București: Editura Economică

Chiaburu, D. S., and Harrison, D. A. (2008). Do peers make the place? Conceptual synthesis and meta-analysis of coworker effects on perceptions, attitudes, OCBs, and performance. Journal of applied psychology, 93(5), p.1082

Chou, P. (2015). The effects of workplace social support on employee's subjective well-being. European Journal of Business and Management, 7(6), 8-19.

Cropanzano, R., and Mitchell, M. S. (2005). Social exchange theory: An interdisciplinary review. Journal of management, 31(6), 874-900.

Harris, J. I., Winskowski, A. M., \& Engdahl, B. E. (2007). Types of workplace social support in the prediction of job satisfaction. The career development quarterly, 56(2), 150-156.

Hoffman, B. J., Blair, C. A., Meriac, J. P., and Woehr, D. J. (2007). Expanding the criterion domain? A quantitative review of the OCB literature. Journal of Applied psychology, 92(2), 555.

Janssen, S., Tahitu, J., van Vuuren, M., and de Jong, M. D. (2018). Coworkers' perspectives on mentoring relationships. Group \& organization management, 43(2), pp.245-272.

Jha, S., and Jha, S. (2010). Determinants of organizational citizenship behaviour: A review of literature. Journal of Management \& Public Policy, 1(2).

Lee, K., and Allen, N. J. (2002). Organizational citizenship behavior and workplace deviance: The role of affect and cognitions. Journal of applied psychology, 87(1), p. 131

Liden, R. C., Wayne, S. J., and Stilwell, D. (1993). A longitudinal study on the early development of leader-member exchanges. Journal of Applied Psychology, 78, pp. 662-674.

Muchhal, D. S. (2014). HR practices and Job Performance. IOSR journal of humanities and social science (IOSR-JHSS), 19(4), pp. 55-61.

Nasir, R., Mohammadi, M. S., Wan Shahrazad, W. S., Fatimah, O., Khairudin, R., and Halim, F. (2011). Relationship between organizational citizenship behavior and task performance. The social sciences, 6(4), pp. 307-312

Pânișoară, G. and Pânișoară I.O., 2016. Managementul resurselor umane. $3^{\text {rd }}$ ed., lasi: Polirom.

Park, K. O., Wilson, M. G., and Lee, M. S. (2004). Effects of social support at work on depression and organizational productivity. American journal of health behavior, 28(5), pp. 444-455

Sonnentag, S., Volmer, J., and Spychala, A. (2008). Job performance. The Sage handbook of organizational behavior, 1, 427-447.

Susskind, A. M., Kacmar, K. M., and Borchgrevink, C. P. (2003). Customer service providers' attitudes relating to customer service and customer satisfaction in the customer-service exchange. Journal of Applied Psychology, 88, pp. 179-187. 
Talebzadeh, N., and Karatepe, O. M. (2019). Work social support, work engagement and their impacts on multiple performance outcomes. International Journal of Productivity and Performance Management.

Tambe, S., and Shanker, M. (2014). A Study of Organizational Citizenship Behavior (OCB) And Its Dimensions: A Literature Review. 70 International Research Journal of Business and Management-IRJBM.

Tran, K. T., Nguyen, P. V., Dang, T. T., and Ton, T. N. (2018). The impacts of the high-quality workplace relationships on job performance: a perspective on staff nurses in Vietnam. Behavioral sciences, 8(12), p. 109. 